\title{
Synthesis of NbFAP0-5 and NbFAPSO-5 Molecular Sieve by Hydrothermal Method and Comparison of Their XRD Patterns and Their Acidic Properties Evaluation by Infrared Spectroscopy
}

\author{
Mominou Nchare ${ }^{1 *}$, Lei Wang ${ }^{2}$, Salomon Anagho ${ }^{3}$ \\ ${ }^{1}$ Department of Mining \& Extractive Metallurgy, School of Geology \& Mining Engineering, University of \\ Ngaoundéré, Ngaoundéré, Cameroon \\ ${ }^{2}$ Shanghai Institute of Technology, Shanghai, China \\ ${ }^{3}$ Department of Chemistry, University of Dschang, Dschang, Cameroon \\ Email: "nmominou@yahoo.com
}

Received 21 December 2015; accepted 25 June 2016; published 28 June 2016

Copyright $@ 2016$ by authors and Scientific Research Publishing Inc.

This work is licensed under the Creative Commons Attribution International License (CC BY).

http://creativecommons.org/licenses/by/4.0/

(c) (i) Open Access

\begin{abstract}
Mesoporous molecular sieves, NbFAPO-5 and NbFAPSO-5 were hydrothermally synthesized with AlPO-5 type structure. Characterization of these molecular sieves was performed by X-ray diffraction to determine their structure, ICP-EAS for their elemental composition and infrared spectrometry to access their acidic properties. X-ray diffraction patterns confirmed well AlPO-5 type structure. ICP-EAS analysis confirmed the incorporation of silicon $(12.9 \%)$, aluminium $(15.4 \%)$, phosphorous (21.9\%), iron (5.62\%) and niobium (0.39\%) into AlPO-5 framework. Infrared spectrometry analysis showed that both Bronsted and Lewis sites were found in the synthesized samples. The presence of both Bronsted and Lewis acid site led to bifunctional function of NbFAPO-5 and NbFAPSO-5 molecular sieve in promoting both oxidation and esterification reactions. NbFAPSO-5 Bronsted acidity was higher than that of NbFAPO-5 and for Lewis acidity, NbFAPO-5 was higher than that of NbFAPO-5.
\end{abstract}

\section{Keywords}

Niobium, AlPO-5 Molecular Sieve, Hydrothermal Synthesis, Acid Properties

\footnotetext{
${ }^{*}$ Corresponding author.
} 


\section{Introduction}

Catalyst technology has increasingly played a key role in the economic development of countries around the word. Today, most of the chemicals, polymers, drugs, dyes and fabrics are prepared by using catalysts [1]. The discovery of new catalysts and their applications has historically led to major innovations in chemical processing. In recent years the isomorphous substitution in zeolite and aluminophosphate materials by other elements has been extensively studied and reviewed [2]. Isomorphous substitution of elements in these materials is carried out in order to modify their catalytic and shape selective properties. Different ways to perform such substitutions are well established either during hydrothermal synthesis or by post-synthesis methods in liquid and vapor phase [3]-[5]. Generally hydrothermal synthesis is preferred over post synthesis because it leads to better incorporation of a wide variety of metal ion into aluminophosphate materials which are of particular interest for the design of novel catalysts. The past decade has brought an increasing interest in niobium-containing materials, which can be applied within many fields [6]. Niobium compounds exhibit special properties not shown by the compounds of neighboring elements in the periodic table. Some of them like stability, or strong metal support interaction are very important for good quality catalyst. The unfavorable feature of niobium oxides, the biggest group of niobium compounds applied in heterogeneous catalysis is a low mobility and reducibility of niobium species.

In this work, Nb was successfully introduced into FAPO-5 and FAPSO-5 type structure leading to NbFAPO-5 and NbFAPSO-5 and their acidic properties studied.

\section{Experimental Procedures}

\subsection{Synthesis of AlP0-5 Molecular Sieve [7] [8]}

In $50 \mathrm{ml}$ Erlern Mayer, a fixed amount of deionized water was added with 85\% phosphoric acid and just after aluminum source was slowly added under stirring which took 20 minutes.

After adding the template (Triethylamine), the temperature was rised to $40^{\circ} \mathrm{C}$ and the whole mixture was then stirred for another 30 minutes. The resulting mixture was then placed into a Teflon-line stainless steel autoclave and heated at $200^{\circ} \mathrm{C}$ for 24 hours. After quenching to the room temperature, the product was washed repeatedly with deionized water, and then dried at $100^{\circ} \mathrm{C}$ for 4 hours. The resulting product was calcined at $600^{\circ} \mathrm{C}$ for 4 hours.

The synthesis of FeAIPO- 5 follows the same procedure as described for $\mathrm{AIPO}_{4}-5$. With any priority, the iron source was added before aluminum source. The synthesis of FeAPSO- 5 also follows the procedure described for $\mathrm{FeAIPO}_{4}$-5. Silicon source was added just after aluminum had form a homogenized mixture.

For the niobium solution preparation, a fixe quantity of niobium hydroxide was put in $80 \mathrm{~g}$ oxalic acid and $500 \mathrm{ml}$ deionized water under stirring, and the temperature was rised to $70^{\circ} \mathrm{C}-80^{\circ} \mathrm{C}$. After a period of time, a clear solution of niobium complexed in oxacilic acid was obtained.

Synthesis of NbFeAPO-5 and NbFeAPSO-5 follows the same procedure as described for FeAPO-5 and FeAPSO-5 except that niobium solution was added just after putting aluminum source for NbFeAPO-5 and silicon source for NbFeAPSO-5.

The raw materials for different synthesized catalysts are found in Table 1.

\subsection{Product Analysis}

$\mathrm{X}$-ray powder diffraction data were obtained on a Rigaku D/max diffractometer using $\mathrm{Cu}$ ka radiation at $40 \mathrm{kv}$ and $60 \mathrm{Ma}$. Elemental composition of different catalysts was accessed using ICP-AES performed on IRIS 1000 and the acidity by mean of infrared spectrometry performed on Nicolet Magna-IR 550.

\section{Results and Discussion}

\subsection{Effect of Iron Content in NbFAPSO-5 Molecular Sieve}

Samples with iron content of $2.02 \mathrm{~g}$ (Figure 1) and $4.04 \mathrm{~g}$ (Figure 2) were prepared and the resulting XRD patterns confirm well that of published data [9].

Because the amount of iron incorporated is rather low, therefore changes in XRD patterns are not observed. Access inside the behavior of the iron incorporating AFI framework, using energy minimization technique [6], shows that the substitution of $\mathrm{Fe}$ (III) for Al (III) in the AIPO-5 framework is energetically unfavorable, producing 
Table 1. Catalysts raw materials.

\begin{tabular}{cccccc}
\hline $\begin{array}{c}\text { Raw } \\
\text { materials }\end{array}$ & Specifications & $\begin{array}{c}\text { Molecular } \\
\text { formula }\end{array}$ & $\begin{array}{c}\text { Molecular } \\
\text { weight (g/mol) }\end{array}$ & Purity & Vendor \\
\hline $\begin{array}{c}\text { Phosphoric acid } \\
\text { Boehmite }\end{array}$ & AR $500 \mathrm{ml}$ & $\mathrm{H}_{3} \mathrm{PO}_{4}$ & 98.0 & $85.0 \%$ & Guanzhou Rikewei Chemical Co., Ltd \\
$\begin{array}{c}\text { Triethylamine } \\
\text { Niobium hydroxide }\end{array}$ & AR $500 \mathrm{ml}$ & $\mathrm{Al}_{2} \mathrm{O}_{3} \cdot 2 \mathrm{H}_{2} \mathrm{O}$ & 138.0 & $95 \%$ & Zibo Yinghe Chemicals Co., Ltd \\
Ferric nitrate & AR $500 \mathrm{~g}$ & $\left.\mathrm{~g} \mathrm{C}_{2} \mathrm{H}_{5}\right)_{3} \mathrm{~N}$ & 101.19 & $\geq 99.0 \%$ & Shanghai Ruizheng Chemicals. Co., Ltd \\
Ethyl orthosilicate & AR $500 \mathrm{ml}$ & $\mathrm{Nb}(\mathrm{OH})_{5}$ & 177.94 & $99.9 \%$ & Guanzhou Non-Ferrous Metals Co., Ltd \\
\hline
\end{tabular}

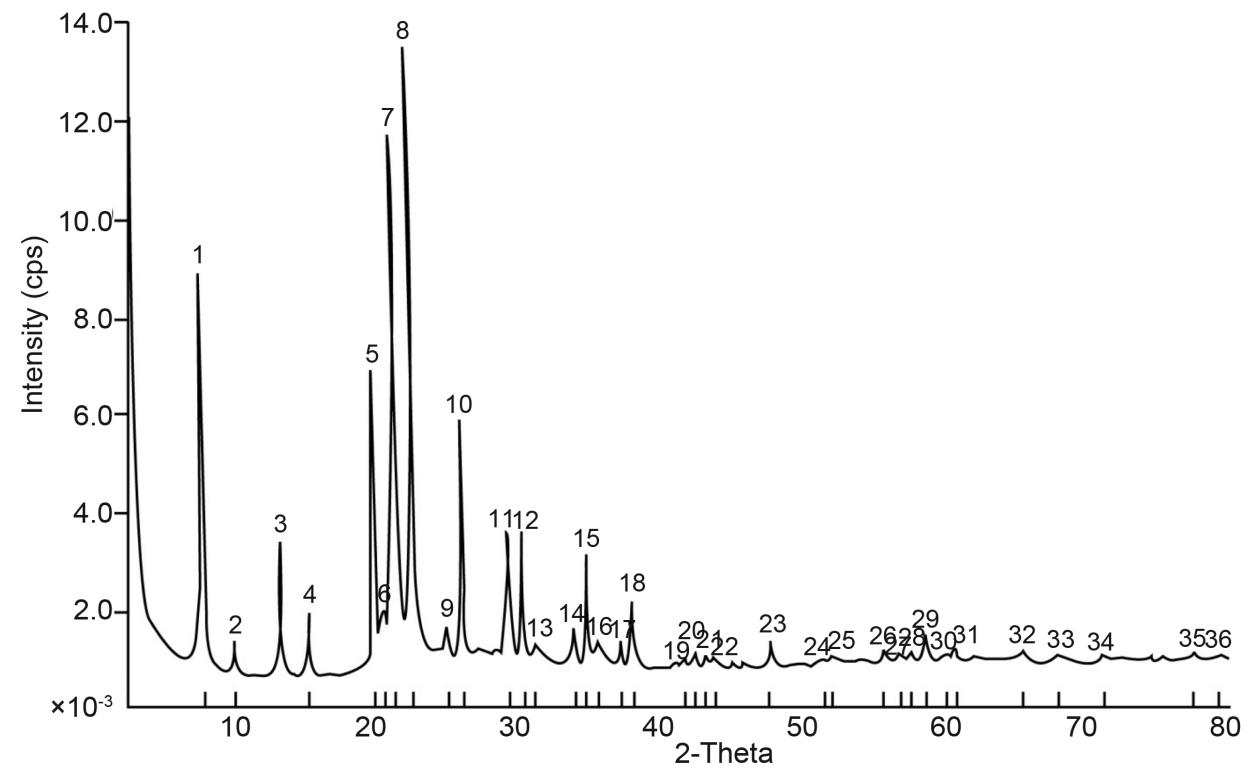

Figure 1. XRD patterns of synthesized samples with iron content of $2.02 \mathrm{~g}$.

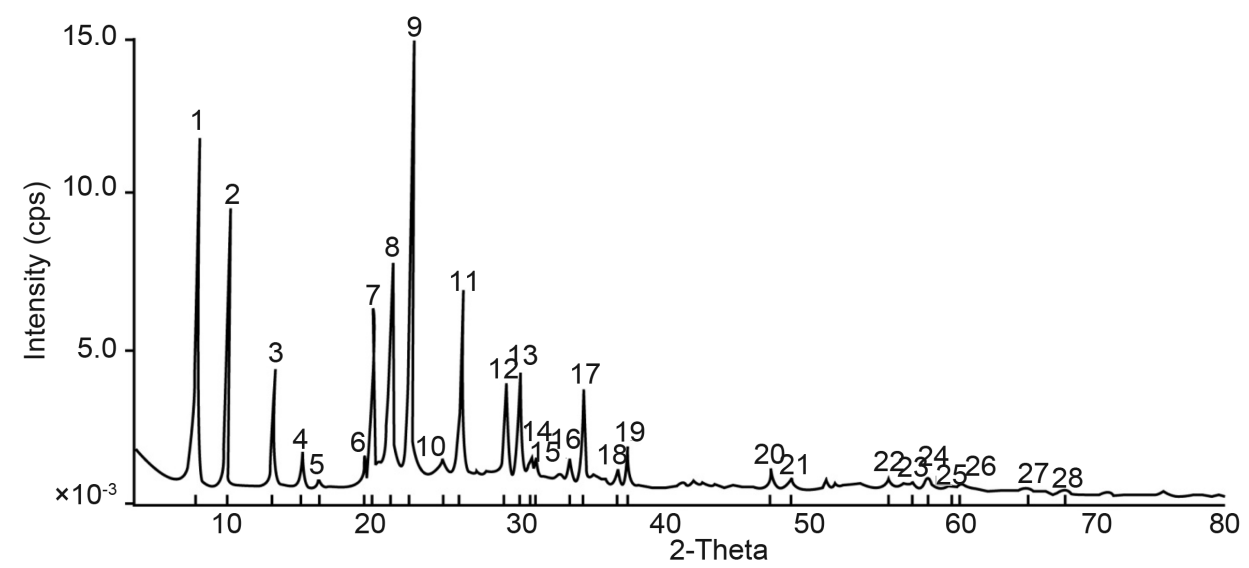

Figure 2. XRD patterns of synthesized sample with iron content of $4.04 \mathrm{~g}$.

strong distortion around the Fe atom. According to this study, Fe (III) in tetrahedral sites destabilizes, but does not disrupt the structure. Fe incorporation increases the T-O distance, resulting in strong distortion of the framework. This is due to the fact that Fe-O distance is approximately larger than the Al-O one, and also owing to differences in tetrahedral atoms ( $\mathrm{Al}, \mathrm{Fe})$-Oxygen distances, the cell parameters will vary. 


\subsection{Effect of Silicon Content in NbFAPSO-5 Molecular Sieve}

High silicon content in NbFAPSO-5 molecular sieve result in the disturbance of XRD patterns. In this study, $1 \mathrm{ml}$ to $3 \mathrm{ml}$ was successfully introduced into FAPO-5 molecular sieve without resulting in XRD patterns disturbance as shown in Figure 3 and Figure 4.

Adding silicon into FAPO-5 resulted in the increase of acidic properties of these materials, by the formation of $\mathrm{SiO}_{2}-\mathrm{Al}_{2} \mathrm{O}_{3}$ oxides, which also increase the stability of this molecular sieve. Elemental analysis using ICPAES technique shows that silicon content up to $12.9 \%$ was successfully incorporated into our prepared samples, maintaining AFI type structure. A fundamental question that arises regarding the substitution of silicon into the AIPO-5 structural framework is the location of this substituted ion. Silicon theoretically can substitute for aluminum or phosphorous, or both. If the silicon substitutes for aluminum, the charged on the framework will be positive, giving rise to anion exchange properties; substitution for phosphorous will result in anionic framework

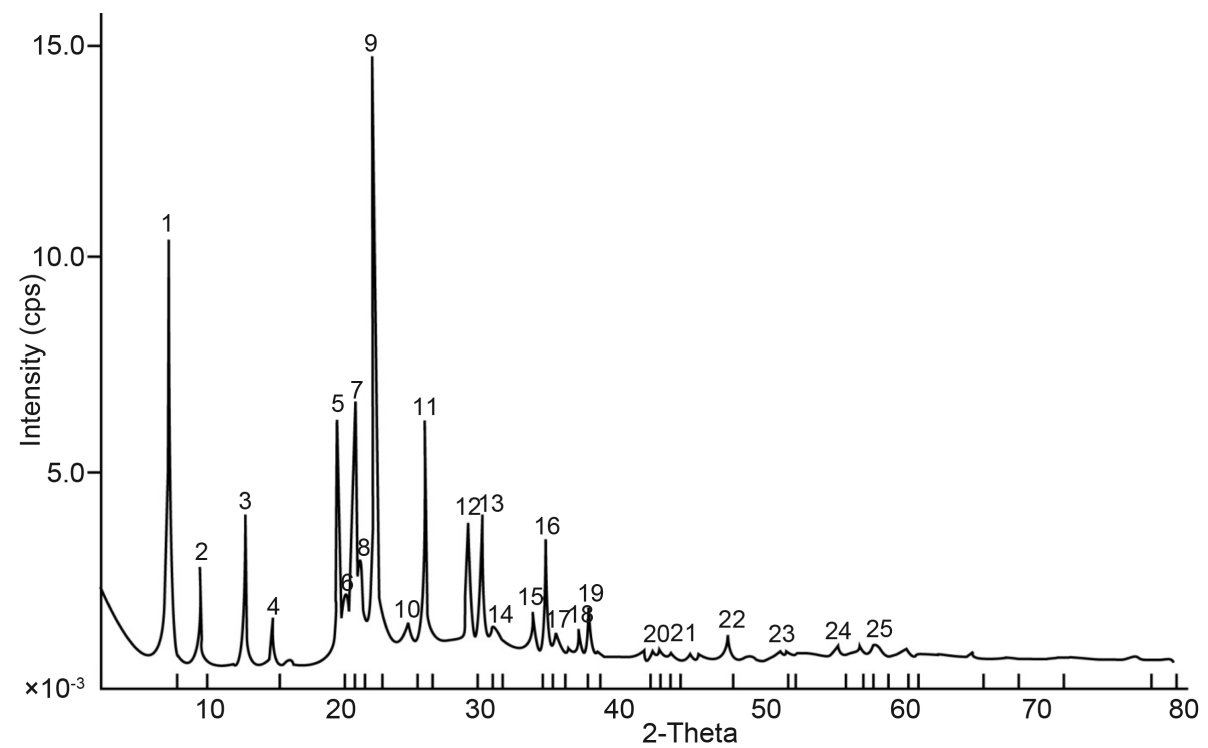

Figure 3. XRD patterns of silicon containing NbFAPSO-5 molecular sieve with silicon content of $1 \mathrm{ml}$.

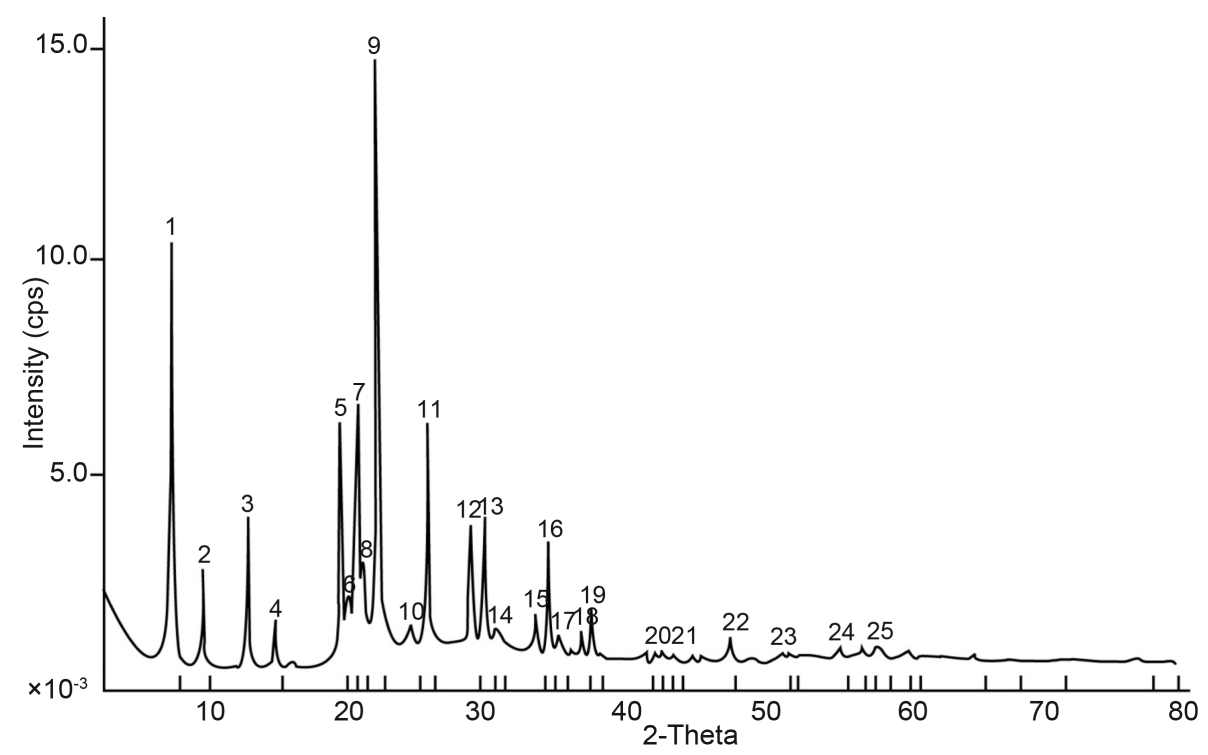

Figure 4. XRD patterns of silicon containing NbFAPSO-5 molecular sieve with silicon content of $3 \mathrm{ml}$. 
similar to the zeolite molecular sieve; no net change in the framework will be observed if both aluminum and phosphorous are simultaneously substituted with two silicon atoms. The ability to exchange cations as well as observed acid activity in SAPO-5 materials indicates that the silicon does, indeed, substitute for phosphorous. SAPO-5 (AFI) has mole fraction for $\mathrm{Si}_{x} \mathrm{AI}_{\mathrm{y}} \mathrm{P}_{\mathrm{z}}$ with $\mathrm{x}+\mathrm{y}$ greater than $\mathrm{z}$, which is evidence for substitution of two silicon atoms for $(\mathrm{AI}+\mathrm{P})$ in addition to substitution of silicon for phosphorous.

\subsection{Effect of Nb Content in NbFAPSO-5 Molecular Sieve}

Two sources of niobium were tested, niobium pentaoxide and niobium hydroxide. The first resulted in low solubility; niobium hydroxide complexed easily in oxalic acid as described in experimental section. The XRD patterns of NbFAPO-5 are shown in Figure 5 and that of NbFAPSO-5 in Figure 6. Compositional analysis of the synthesized samples NbFAPO- 5 and NbFAPSO-5 showed that $39 \%$ of niobium was confirmed to be incorporated while maintaining AIPO-5 type structure.

\subsection{Effects of Crystallization Temperature, Time and Template in NbFAPO-5 and NbFAPSO-5}

The synthesis of NbFAPO-5 and NbFAPSO-5 exhibits many similarities to that of aluminosilicate molecular sieves. All are synthesized from reactive gels under the $\mathrm{pH}$ of 4 to 7 , with the presence of organic additives helping

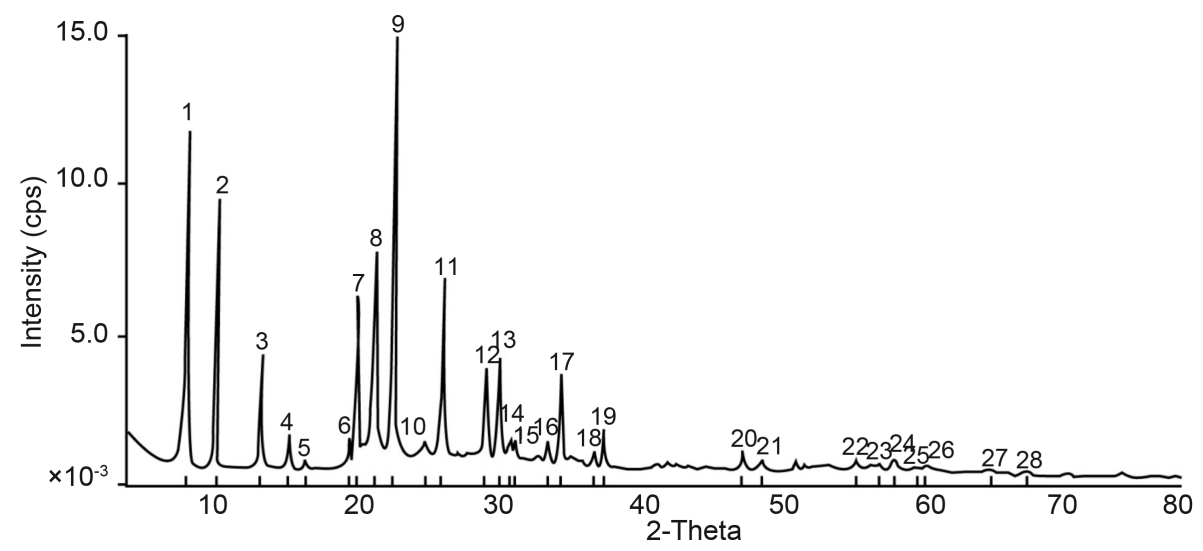

Figure 5. XRD patterns of niobium containing NbFAPO-5.

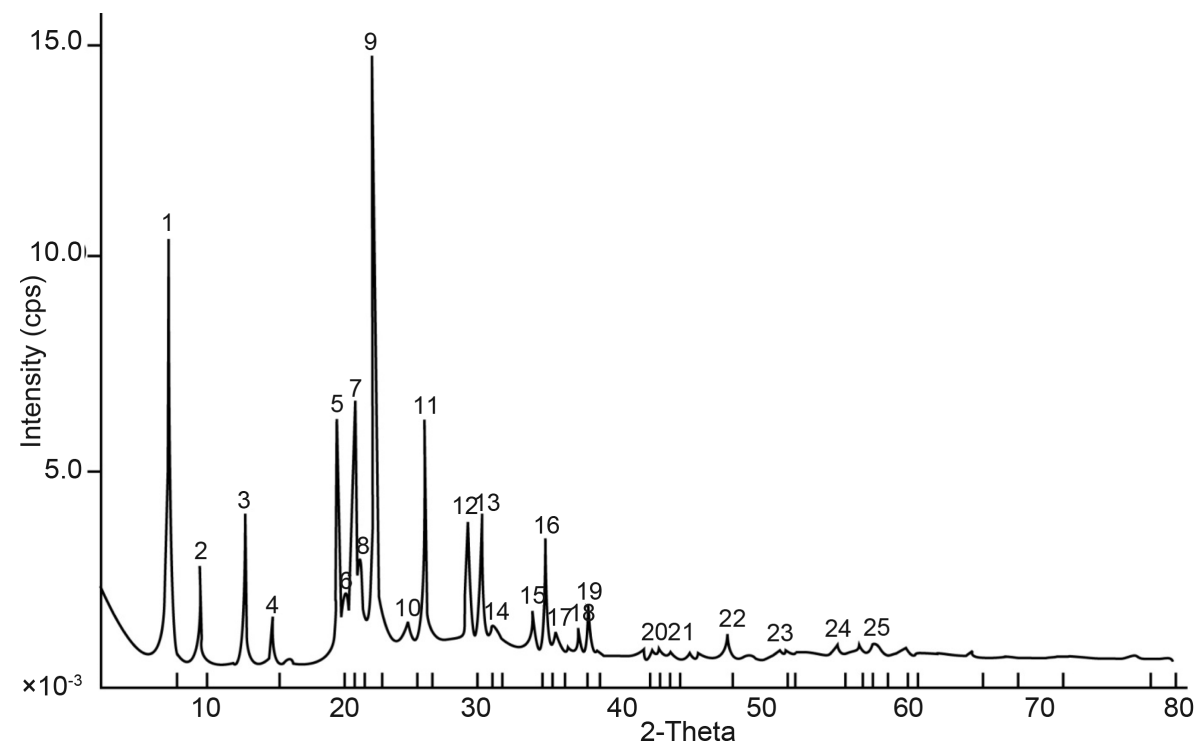

Figure 6. XRD patterns of niobium containing NbFAPSO-5. 
to promote crystallization of a specific phase.

Temperature plays an important role in the crystallization of these synthesized samples. At lower temperature $\left(100^{\circ} \mathrm{C}-125^{\circ} \mathrm{C}\right)$ AFI type structure was not obtained; this structure occurred only for temperature ranging from $150^{\circ} \mathrm{C}$ to $200^{\circ} \mathrm{C}$. At higher crystallization temperature $\left(200^{\circ} \mathrm{C}\right)$, other non-zeolitic phases are observed to crystalllize with increased crystallization time. The optimum time needed to promote crystallization of these phases appears to be dependent on both the temperature and the nature of the organic species used in the reaction mixture.

The organic additives appear to promote crystallization of a specific aluminophosphates structure, although it is unclear if it is in the same way that the organic additive promotes crystallization of a specific structure in the synthesis of the aluminosilicates. Many organic amines have been claimed to promote the crystallization of the $\mathrm{AIPO}_{4}-5$ structure; but there appears to be little correlation among them. A wider range of neutral organic amines have been found to aid in crystallization of aluminophosphates structures, compared to the aluminosilicate system; however, this may be a result of the initially acidic environment of the aluminophosphates gel, which would encourage the formation of a protonated amine, thus generating the cationic form in situ. The preparation of several structures from a given organic amine is a result of changing other synthesis conditions.

\subsection{Acidic Properties}

Infrared spectra of different synthesized samples show three distinct regions. Peaks at 1450 and $1540 \mathrm{~cm}^{-1}$ are assigned to Lewis and Brönsted acid sites respectively. According to Fateley [10], peak at $1500 \mathrm{~cm}^{-1}$ is assigned to the C-H bending vibrations of triethylamine template incorporated in AFI channels.

The infrared spectrum of FAPO-5 molecular sieve is shown in Figure 7.

From Figure 7, we can see that there is an expressed peak at ca. $1450 \mathrm{~cm}^{-1}$ after evacuation at $200^{\circ} \mathrm{C}$ and no peak at ca. $1450 \mathrm{~cm}^{-1}$. Evacuation at $350^{\circ} \mathrm{C}$ shows a light peak at ca. $1450 \mathrm{~cm}^{-1}$ which mean that in this molecular sieve, exist only strong and weak Lewis acidity. FAPO-5 molecular sieve has small number of the aluminum atoms substituted with iron while retaining the charge neutrality of the framework; therefore, no Brönsted sites are present.

After incorporation of Nb into FAPO-5 molecular sieve, NbFAPO-5 sample is obtained. The resulting infrared spectrum of pyridine chemisorption is shown in Figure 8.

From Figure 8, we can see that at $200^{\circ} \mathrm{C}$, two peaks are observed; one at $1450 \mathrm{~cm}^{-1}$ and another with low intensity at $1450 \mathrm{~cm}^{-1}$. Treatment at $350^{\circ} \mathrm{C}$ does not show peak, both at 1450 and $1540 \mathrm{~cm}^{-1}$, meaning that there exist only weak Brönsted and Lewis acidity in this molecular sieve.

Infrared spectra of FAPSO-5 are shown in Figure 9. Treatment at $200^{\circ} \mathrm{C}$ shows an expressed peak at 1450 and light intensity peak at $1450 \mathrm{~cm}^{-1}$. Treatment at $350^{\circ} \mathrm{C}$ does not show peak at $1450 \mathrm{~cm}^{-1}$ meaning that in this molecular sieve both strong and weak Lewis acid sites exist with strong Brönsted acid sites.

Incorporation of $\mathrm{Nb}$ into FAPSO-5, leading to NbFAPSO-5 molecular sieve, infrared spectrum is shown in Figure 10.

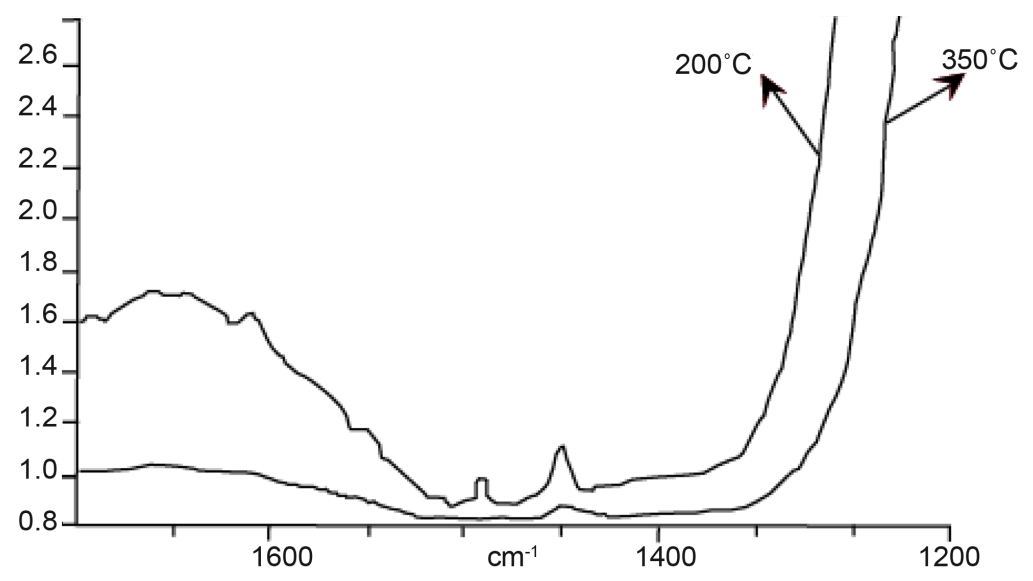

Figure 7. Infrared spectrum of FAPO-5. 


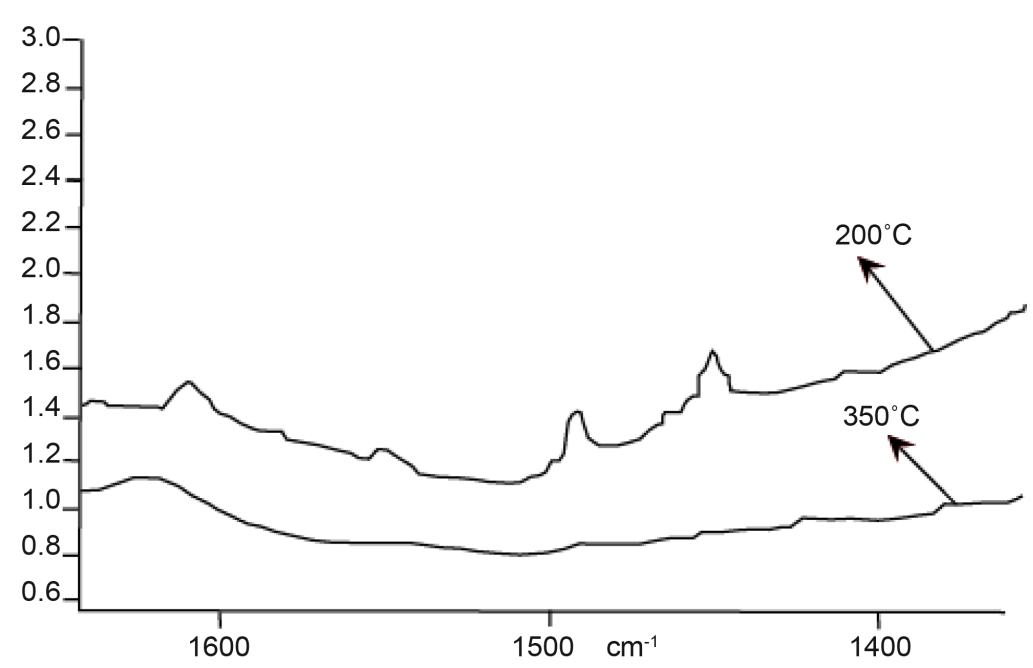

Figure 8. Infrared spectrum of NbFAPO-5.

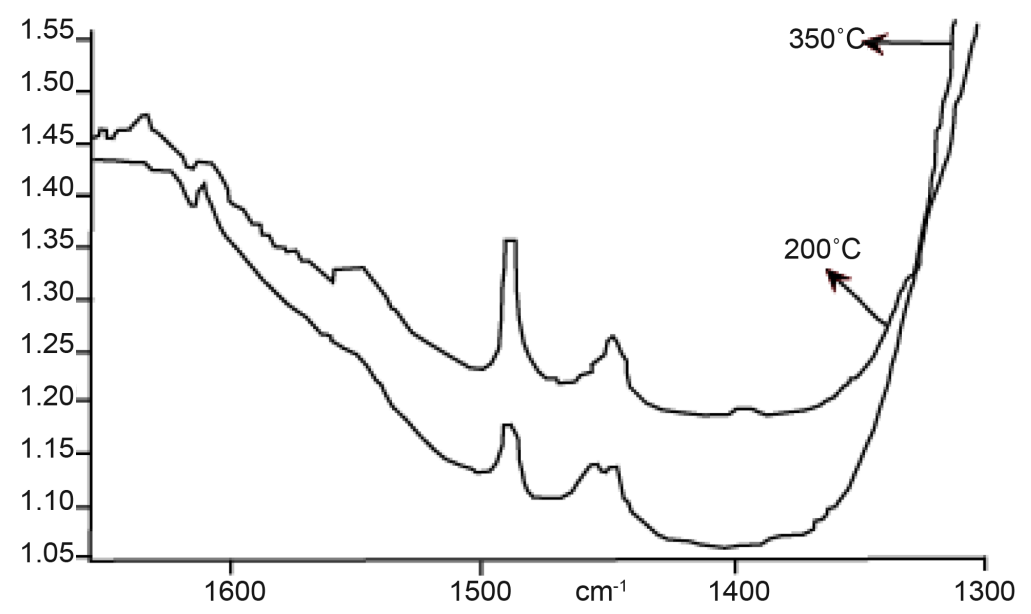

Figure 9. Infrared spectrum of FAPSO-5.

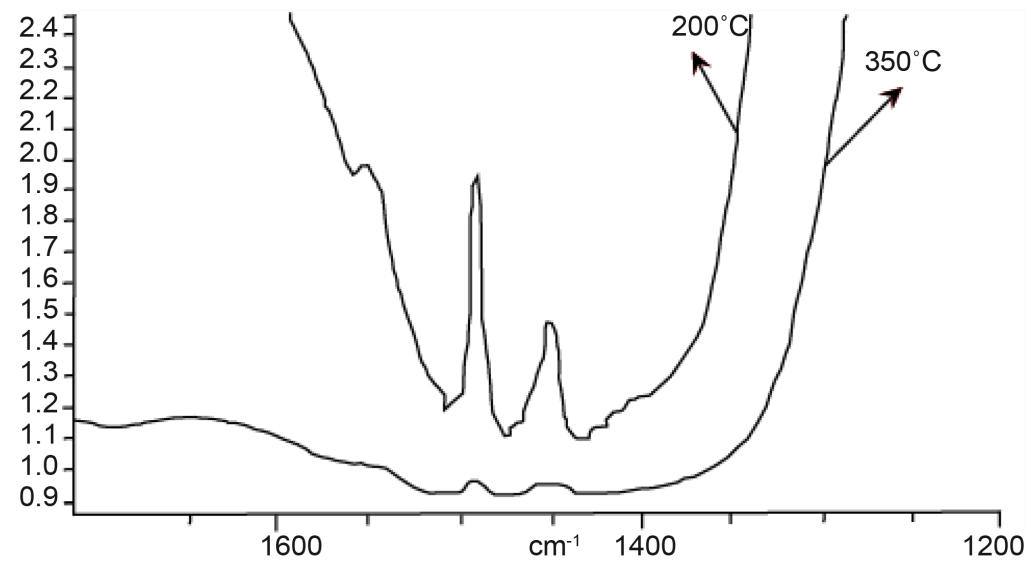

Figure 10. Infrared spectrum of NbFAPSO-5.

Adsorption of probe molecule behaves in the same manner as in FAPSO-5. Brönsted and Lewis acidity of different synthesized samples are shown in Table 2.

From Table 2, we can see that incorporating Nb in FAPO-5 catalysts increases both Lewis and Brönsted acidity, 
Table 2. Lewis and Brönsted acid in FAPO-5, NbFAPO-5, FAPSO-5 and NbFAPSO-5.

\begin{tabular}{ccccccc}
\hline Acidity Catalysts & TL & TB & SL & SB & WL & WB \\
NbFAPO-5 & 36.33 & 26.33 & 0 & 0 & 36.33 & 26.334 \\
FAPO-5 & 15.77 & 0 & 6.266 & 0 & 0 & 0 \\
NbFAPSO-5 & 28.646 & 28.809 & 0 & 0 & 9.512 & 28.809 \\
FAPSO-5 & 33.533 & 84.645 & 31.44 & 0 & 0 & 84.645
\end{tabular}

$\mathrm{TL}=$ total Lewis acid, TB = total Brönsted acid, SL = strong Lewis acid, SB = strong Brönsted acid, WL = weak Lewis acid, WB = weak Brönsted acid.

meaning furthermore his presence in FAPO-5 framework. Incorporation in FAPSO-5 leads to a decrease in acidity, where Brönsted and Lewis acid are nearly at equilibrium. This behavior is of great importance for this molecular sieve which should promote both oxidation and esterification reactions. The presence of only weak Brönsted acidity can be attributed to structural defects leading to terminal P-OH and Al-OH. The occurrence of weak and strong Lewis sites on this solid supports the idea of structural breakage after calcinations to yield defective Al sites. The incorporation of silicon in FAPO-5 catalyst generates a relatively high proportion of Brönsted acid sites.

\section{Conclusion}

Using triethylamine as template, boemite as aluminium source, phosphoric acid as phosphorous source, ferricnitrate as iron source, orthosilicate as silicate source, niobium hydroxide as niobium source, it was possible to hydrothermally synthesize AlPO-5, FAPO-5, NbFAPO-5 and NbFAPSO-5 molecular sieve with AFI type structure. Both Lewis and Brönsted acidity were found in the synthesized samples. Incorporation of niobium into FAPSO-5 framework should be done carefully because high content will lower the acidity, and also diminish the molecular sieve crystallinity.

\section{Acknowledgements}

Special thanks are due to Mr. Toumbe Mama and Dr. Mbowou Isaack for their technical assistance to accomplish this work.

\section{References}

[1] Fleischmann, C., Lievenbrück, M. and Ritter, H. (2015) Polymers and Dyes: Developments and Applications. Polymers, 7, 717-746. http://dx.doi.org/10.3390/polym7040717

[2] Hartman, M. and Kevan, L. (2002) Substitution of Transition Metal Ions into Aluminophosphates and Silicoaluminophosphates: Characterization and Relation to Catalysis. Research on Chemical Intermediates, 28, 625-695. http://dx.doi.org/10.1163/15685670260469357

[3] Tuel, A. (1995) $\mathrm{Fe}^{3+}$ and $\mathrm{Ti}^{4+}$ Incorporating Zeolite Framework. Zeolites, 15, 228-235. http://dx.doi.org/10.1163/15685670260469357

[4] Flanigen. (1986) New Development in Zeolites. Studies in Surface Science and Catalysis, 28, 103.

[5] Sheldon, R.A. (1997) Innovation in Zeolites Materials Sciences. Catalysis, 68, 381-388.

[6] Ziolek, M. (2003) Niobium-Containg Catalysts-The State of the Art. Catalysis Today, 78, 47-64. http://dx.doi.org/10.1016/S0920-5861(02)00340-1

[7] Gonzales, J.G. and Delacruz, J. (1999) Computational Study of Substitution of Al by Fe ${ }^{3+}$ in the AlPO-5 Framework. Microporous and Mesoporous Materials, 29, 361-365. http://dx.doi.org/10.1016/S1387-1811(99)00005-0

[8] Wilson, S.T., Flanigen, E.M. and Pfaff, C. (1982) Crystalline Metallophosphate Composition. USP 4310440.

[9] Qiu, S., Pang, W., Kessler, H. and Guth, J.L. (1989) Collection of Simulated XRD Powders Patterns for Zeolites. Zeolites, 9, 440-444.

[10] Perez O., J.O., Borade, R.B. and Clearfield, A. (1998) Synthesis of a Mesoporous Aluminophosphate. Journal of Molecular Structure, 470, 221-228. http://dx.doi.org/10.1016/S0022-2860(98)00484-0 


\section{Submit or recommend next manuscript to SCIRP and we will provide best service for you:}

Accepting pre-submission inquiries through Email, Facebook, Linkedin, Twitter, etc A wide selection of journals (inclusive of 9 subjects, more than 200 journals)

Providing a 24-hour high-quality service

User-friendly online submission system

Fair and swift peer-review system

Efficient typesetting and proofreading procedure

Display of the result of downloads and visits, as well as the number of cited articles

Maximum dissemination of your research work

Submit your manuscript at: http://papersubmission.scirp.org/ 